\title{
Genome-wide identification of miRNAs and IncRNAs in Cajanus cajan
}

Chandran Nithin ${ }^{1 \dagger}$, Amal Thomas ${ }^{1,3 \dagger}$, Jolly Basak ${ }^{2^{*}}$ and Ranjit Prasad Bahadur ${ }^{1 *}$ (D)

\begin{abstract}
Background: Non-coding RNAs (ncRNAs) are important players in the post transcriptional regulation of gene expression (PTGR). On one hand, microRNAs (miRNAs) are an abundant class of small ncRNAs ( $22 \mathrm{nt}$ long) that negatively regulate gene expression at the levels of messenger RNAs stability and translation inhibition, on the other hand, long ncRNAs (IncRNAs) are a large and diverse class of transcribed non-protein coding RNA molecules (> 200nt) that play both up-regulatory as well as down-regulatory roles at the transcriptional level. Cajanus cajan, a leguminosae pulse crop grown in tropical and subtropical areas of the world, is a source of high value protein to vegetarians or very poor populations globally. Hence, genome-wide identification of miRNAs and IncRNAs in C. cajan is extremely important to understand their role in PTGR with a possible implication to generate improve variety of crops.

Results: We have identified 616 mature miRNAs in C. cajan belonging to 118 families, of which 578 are novel and not reported in MirBase21. A total of 1373 target sequences were identified for 180 miRNAs. Of these, 298 targets were characterized at the protein level. Besides, we have also predicted 3919 IncRNAs. Additionally, we have identified 87 of the predicted IncRNAs to be targeted by 66 miRNAs.

Conclusions: miRNA and IncRNAs in plants are known to control a variety of traits including yield, quality and stress tolerance. Owing to its agricultural importance and medicinal value, the identified miRNA, IncRNA and their targets in C. cajan may be useful for genome editing to improve better quality crop. A thorough understanding of ncRNA-based cellular regulatory networks will aid in the improvement of C. cajan agricultural traits.
\end{abstract}

Keywords: miRNA, IncRNA, Cajanus Cajan, SSR signature, genome-wide analysis

\section{Background}

Cajanus cajan is a major source of protein for the poor communities of many tropical and subtropical regions of the world [1]. The high protein and carbohydrate contents make it not only important to the human diet, but also suitable as high protein feed and fodder ingredient to livestock [2]. With its greater tolerance to heat, drought, and low soil fertility, C. cajan is a valuable component of low external input agricultural farming systems where the farmers have scarcity of resources [3-6]. C. cajan is a good source of sulphur containing amino acids, crude fibre, iron, sulphur, calcium, potassium, manganese and water soluble vitamins especially thiamine, riboflavin and

\footnotetext{
* Correspondence: jolly.basak@visva-bharati.ac.in;

r.bahadur@hijli.iitkgp.ernet.in

†Equal contributors

${ }^{2}$ Department of Biotechnology, Visva-Bharati, Santiniketan, India

${ }^{1}$ Computational Structural Biology Lab, Department of Biotechnology, Indian

Institute of Technology Kharagpur, Kharagpur, India

Full list of author information is available at the end of the article
}

niacin $[7,8]$. In addition to these, several flavonoids, isoflavonoids, tannins and protein fractions have been isolated from the different parts of $C$. cajan and their medicinal uses have been established [9].

The ncRNAs are a wide class of non-coding RNAs that are transcribed but not translated and play a major role in post-transcriptional gene regulations. Based on their length, ncRNAs are generally classified into small noncoding RNAs (sncRNAs) and long non-coding RNAs (lncRNAs). MicroRNAs (miRNA) are an abundant class of sncRNAs ( 22nt long), which negatively regulate gene expression at the levels of messenger RNAs (mRNAs) stability and translation inhibition. In addition to this, the miRNAs are also known to interact with lncRNAs as well as competing endogenous RNAs (ceRNAs) that derepress the gene expression. Identification of the various miRNAs and their targets is important in understanding the dynamics of gene regulation and in designing new breeds of crops with higher productivity and better disease 
resistance. In spite of having immense importance, there are only few studies have ventured into identifying the miRNAs in C. cajan [10]. Additionally, miRNAs of $C$. cajan are still missing in miRBase 21 [11].

The miRNAs are known to have sequence conservation and are grouped into various miRNAs families in miRBase. The presence of orthologs and paralogs among miRNA sequences allows the identification of miRNAs by using computational methods starting from the sequence similarity. The mere presence of a sequence match on a genome does not imply that the identified region is a miRNA. miRNA precursor sequences (pre-miRs) are known to have features distinct from other small RNA. The mapping of known miRNAs to the genome followed by extraction and analysis of pre-miRs is an effective strategy in miRNA discovery [10, 12-17]. Various sequence based information as well as structural attributes of the pre-miRs can be useful to establish whether a given match is a miRNA sequence or not. To begin with, the miRNA precursors have a distinct range in which the nucleotide composition falls [18]. The pre-miRNAs also have a distinct pattern in the free energy of folding [19]. The minimal folding energy index (MFEI), which is the free energy associated with folding, normalized per GC content per hundred nucleotides, is used as a parameter in predicting miRNAs. The miRNAs are also shown to have distinct region in the probability distributions of RNA folding measures, namely, normalized Shannon entropy (NQ), normalized base pairing propensity $(\mathrm{Npb})$ and normalized base pairing distance (ND) [16]. Simple sequence repeats (SSRs) are one to six nucleotides long repeat sequences present in the pre-miRs [20], and can be used as a parameter to efficiently predict miRNAs [16].

lncRNAs are a large and diverse class of transcribed non-protein coding RNA molecules with a length of more than 200 nucleotides. The evidence for regulatory role of lncRNAs in important biological processes was first identified during the 1980s from genetic analyses of the Drosophila bithorax complex [21]. Compared to the protein coding mRNAs, lncRNAs have certain specific properties, namely, shorter length, lower abundance, restriction to particular tissues or cells and less frequent conservation between species [22]. The lncRNA biogenesis is very similar to protein coding mRNAs but some lncRNAs are transcribed by RNA polymerase III [23]. The lncRNAs also have the posttranscriptional modifications like 5' capping, splicing and polyadenylation [24]. While most of the lncRNAs are localized within the nucleus, there are a few exceptions that perform functions in the cytosol $[25,26]$. The origin of lncRNAs can range from intronic, exonic, intergenic, intragenic, promoter regions, 3'- and 5'- UTRs and enhancer sequences. The transcription of lncRNAs can happen either in sense or in antisense directions [27]. They play both down regulatory as well as up regulatory roles at the transcriptional level. The lncRNAs originating from protein coding loci competes for the RNA polymerase II and other initiation factors or cause the premature termination of elongation complex [28]. The lncRNAs can enhance the accessibility of target site to RNA polymerase and thereby upregulate the gene expression [29]. Some lncRNAs bind to the promoter DNA of target gene, forming a RNAdsDNA triplex that prevents the preinitiation complex from accessing the target gene promoter [30]. There are also lncRNAs which are reported to regulate the gene expression by inhibiting the RNA polymerase activities or by controlling the subcellular localization of transcription factors [31-33]. In addition to the transcriptional regulation, lncRNAs also play a role in post-transcriptional modulations of mRNA processing. They play role in pre-mRNA alternate splicing, transport, translation and degradation [34]. The lncRNAs can also cause the degradation of target mRNA through the formation of a double stranded RNA duplex, which is processed into endo-siRNAs [35].

In this study, we have identified 616 miRNAs in C. cajan, of which 578 are novel and not reported in MirBase21. Besides, we have also predicted 3919 lncRNAs. Additionally, the protein coding genes targeted by many of the miRNAs are identified in this study, facilitating a functional annotation to the predicted miRNAs. Moreover, we have identified the lncRNAs that are targeted by miRNAs. These findings will significantly contribute to the present knowledge of ncRNAs in C. cajan, and will enhance our understanding for genome editing and improving the crop varieties in plants.

\section{Methods}

\section{Dataset collection and preparation}

The dataset of known miRNAs and pre-miRs was downloaded from miRBase 21 [36], which consists of 4800 mature and 8480 pre-miRs belonging to 73 species of Viridiplantae. Besides, we have also downloaded the draft genome sequence of C. cajan [37]. The coding DNA sequences composed of 21,434 transcriptome assembly contigs, ccTAv2.0, was downloaded from Legume Information system [38]. The protein sequences of Viridiplantae was curated from NCBI [39]. The UniProt proteome, UP000075243, with 47,180 entries was downloaded along with the UniProtGOA annotation data [40, 41]. The SWISS-PROT database [42] was downloaded for running the BLAST [43] search.

\section{Prediction of miRNAs}

The dataset of known miRNAs was BLAST searched against the genome of $C$. cajan. The BLAST hits with zero to three mismatches with the known miRNAs were selected, and were further used for analysis in the prediction pipeline. The upstream and downstream nucleotides from the BLAST hit was extracted following Nithin, et al. [16], and the protein coding sequences were removed by performing BLASTX with the protein sequences of 
Viridiplantae. The sequences were selected based on the cut-off value for each of the following parameters: MFEI, NQ, ND, Npb and SSRs [16]. The MFEI value for a sequence of length $\mathrm{L}$ was calculated using the adjusted MFE (AMFE), which represents the MFE for 100 nucleotides.

$$
M F E I=\frac{A M F E}{(G+C) \%} \text { and } A M F E=-\frac{M F E}{L} \times 100
$$

The genRNAstats program [19] was used to calculate the NQ, ND and Npb for all known pre-miRs of Viridiplantae. $\mathrm{Npb}$ is the measure of total number of base pairs present in the RNA secondary structure per length of the sequence, and the value can range from 0.0 (no base-pairs) to $0.5(\mathrm{~L} / 2$ base-pairs) [44]. The base-pairing probability distribution (BPPD) per base in a sequence were measured using NQ [45], while the base-pair distance for all the pair of structures were measured using ND [46]. Both the parameters ND and NQ were calculated from the MaCaskill base pair probability $\mathrm{p}_{\mathrm{ij}}$ between the two bases, $\mathrm{i}$ and $\mathrm{j}$ :

$$
\begin{aligned}
& \text { where } p_{i j}=\sum_{S_{\alpha} \in S(s)} P\left(S_{\alpha}\right) \delta_{i j} \\
& P\left(S_{\alpha}\right)=\frac{e \frac{-E_{\alpha}}{R T}}{\sum_{S_{\alpha} \in S(s)} e \frac{-E_{\alpha}}{R T}} \\
& \text { and } \delta_{i j}= \begin{cases}1, & \mathrm{x}_{\mathrm{i}} \text { pairs } \mathrm{x}_{\mathrm{j}} \\
0, & \text { otherwise }\end{cases} \\
& N Q=-\frac{1}{L} \sum_{i<j} p_{i j} \log _{2}\left(p_{i j}\right) \text { and } N D=\frac{1}{L} \sum_{i<j} p_{i j}\left(1-p_{i j}\right)
\end{aligned}
$$

The signature SSRs for different miRNA families at window size of three were taken from Nithin, et al. [16]. The conserved SSR signatures were normalized per 100 nucleotides $(\mathrm{R})$. The pipeline followed in the prediction of pre-miRs is depicted in Fig. 1.

\section{Prediction of IncRNAs}

The coding DNA sequences (CDS) of C. cajan were used as the starting point for the prediction of lncRNAs. The CDS with length greater than 200 nucleotides [47] were retained and the ORFs were computed using the EMBOSS getorf standalone [48]. The ORFs with length less than 120 amino acids were retained for further analysis [47]. The coding potential for the sequences were checked by two different algorithms: Coding Potential Calculator (CPC), developed on support vector machine [49], and Coding Potential Assessment Tool (CPAT), which is an alignmentfree algorithm [50]. Based on CPC score (S), sequences were classified into non-coding $(\mathrm{S} \leq-0.5)$, neutral $(-0.5<\mathrm{S}$
$<1.0)$ and coding $(\mathrm{S} \geq 1.0)$ [49]. The sequences classified as neutral were further checked by CPAT. Sequences having CPAT score $<0.2$ were classified as ncRNAs [51]. The sequences were further searched using BLASTX [52] against the SWISS-PROT database [42] with an e-value cut-off of 0.001 . Sequences with more than $40 \%$ identity were removed, and the remaining sequences were selected as lncRNAs. The pipeline followed for the prediction is represented as a flowchart in Fig. 2.

\section{Prediction of miRNA targets}

The targets for mature miRNAs were predicted using psRNATarget server [53] by submitting the mature miRNAs as query and the CDS sequences of $C$. cajan as subject. To reduce the number of false predictions, the maximum expectation threshold was set to a stringent value of 2.0. The cut-off length of nucleotides for complementarity scoring, hspsize [54], was set as the length of the mature miRNAs. The maximum energy of unpairing (UPE) the target site was set as $25 \mathrm{kcal}$ [54]. The flanking length around the target site was selected as 17 nucleotides upstream and 13 nucleotides downstream [55]. Due to the variable length of the mature miRNAs, the sequence range of the central mismatch was adjusted as described by Nithin, et al. [16]. To predict the function of the target sequences, the sequences were mapped to the UniProt proteome. The miRNAs, targeting the IncRNAs, were predicted by submitting the mature miRNAs as query and the lncRNAs of C. cajan as subject following the same pipeline. The interaction networks of miRNAs with target mRNAs were constructed using Cystoscape [56].

\section{Results and Discussion Identification of miRNAs}

In this study, we have identified 616 miRNAs from the genome of $C$. cajan by following the prediction pipeline explained in the 'Materials and Methods' section. The method has been computationally validated by predicting the miRNAs of model plants Arabidopsis thaliana and Glycine max. In both the cases, we obtained high specificity and sensitivity [16]. Moreover, we experimentally validated 97 miRNAs, predicted using the pipeline, in a small RNA library prepared from $P$. vulgaris cv. Anupam [16]. Both G. max and $P$. vulgaris are members of Fabaceae family and are phylogenetically closely related species of $C$. cajan. Hence, we believe that our hypothesis for prediction of miRNAs and their targets will also holds for C. cajan.

The known miRNAs of Viridiplantae were BLAST searched against the genome of $C$. cajan with an e-value cutoff of 1000, allowing zero to three mismatches. The mismatches permitted during the BLAST search allows the identification of miRNAs, which are identical to known miRNAs but novel to the plant species that are not reported in the miRBase. From the BLAST search, a total of 1831779306 


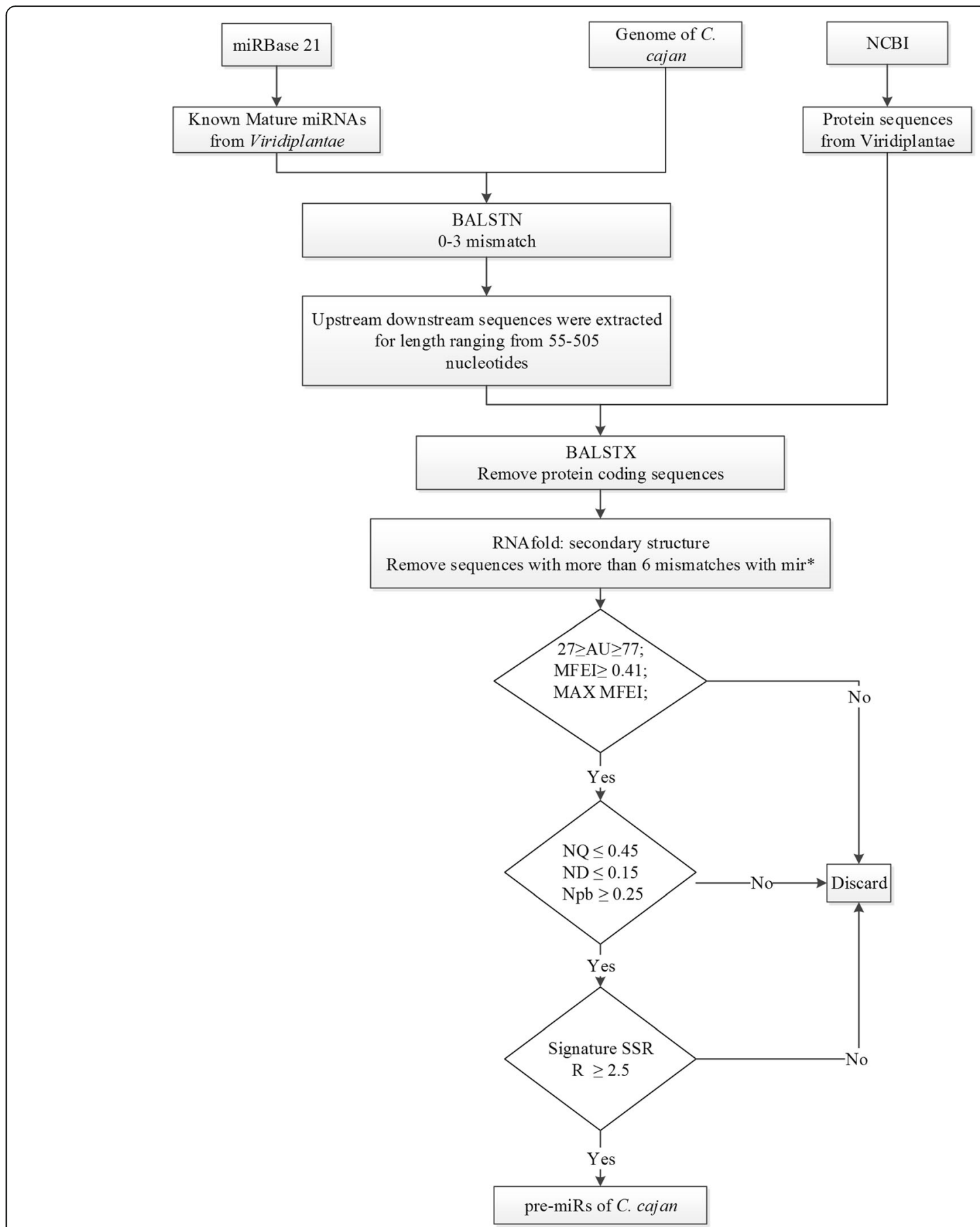

Fig. 1 Schematic representation of the methodology followed in the prediction of pre-miRs of C. cajan

sequences, that do not code for proteins were extracted with all possible lengths. In case of multiple sequences resulting from a single BLAST hit fulfilling the criteria, the one with the maximum MFEI and the maximum $\mathrm{R}$ was retained. A total of 616 miRNAs belonging to 341 miRNA families were identified by the prediction pipeline (Additional file 1: Table S1). A previous study by Kompelli, et al. [10] had identified only 142 miRNAs in C. cajan. This lower number of predicted miRNA may be due to the fact that they have used a smaller search space in identifying miRNAs. Of the miRNAs identified in this study, 578 are novel with respect to both plant miRNAs available in miRBase 21 as well as those identified by Kompelli, et al. [10].

The length of mature miRNAs of C. cajan varies from 15 to 24 nucleotides (nt) with an average of $20 \mathrm{nt}$ (s.d. is \pm 1.4 ). 


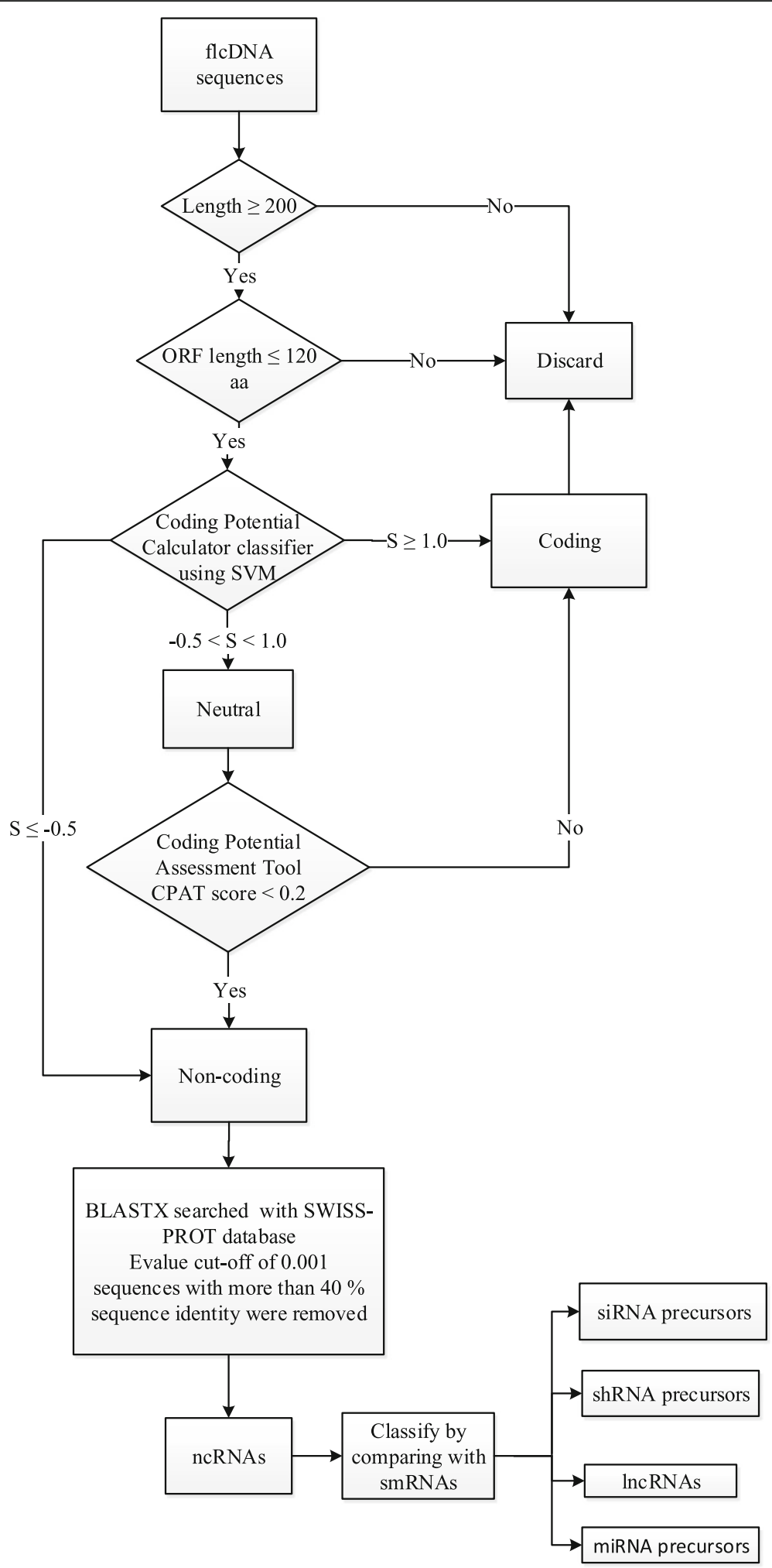

Fig. 2 Schematic representation of the methodology followed in the prediction of IncRNAs of C. cajan 


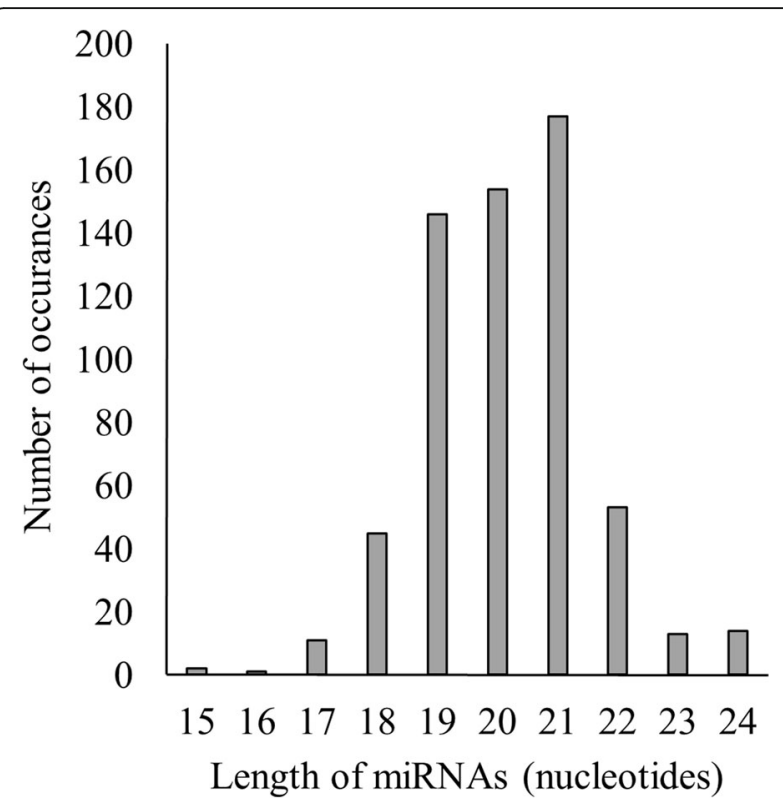

Fig. 3 Distribution of the length of miRNAs in C. cajan

Majority of them (93\%) falls within the range of 18 to $22 \mathrm{nt}$. Figure 3 shows the distribution of length of miRNAs identified in this study. MiRBase 21 has classified the 4800 plant miRNAs into 2290 families. The 616 miRNAs identified in this study belongs to 341 different families (Table 1). The distribution of miRNAs across various families is highly heterogeneous. Majority ( $85 \%$ ) of the families have only either one or two member(s). The highest number of members is observed in the miR171 family followed by miR477, miR169 and miR167 with 14, 10, 9 and 8 members, respectively. In the remaining 49 families, the number of miRNA varies from two to seven (Fig. 4). This distribution is in agreement with the diversity observed in other plant species [57]. Figure 5 shows the distribution of different miRNAs across the 11 chromosomes of C. cajan.

The SSR signatures in various miRNA families of the kingdom Viridiplantae, the family Fabaceae and the species C. cajan are presented in Table 2, while their relative distributions are shown in Fig. 6. We observe only 45 signature SSRs present in the miRNA families of $C$. cajan. The highest frequency is observed for AAU in Viridiplantae, Fabaceae and C. cajan. A total of 19 SSRs are absent in miRNA families of $C$. cajan while 11 of them are present only in one family. The signatures GUG and CCG are absent in other Fabaceae species while they are present in C. cajan. The former signature is present in miR1171 while the latter is present in miR2102 and miR5075 families.

\section{miRNA targets on coding sequences}

The mature miRNAs play a major role in the regulation of gene expression either by inhibiting translation or by degrading coding mRNAs $[58,59]$. The number of targets for an miRNA may range from one to hundreds [60]. However, many mRNA targets in plants contain single miRNAcomplementary site, which perfectly complement with the corresponding miRNAs and cleave the target [61]. We have used the psRNATarget server for the prediction of miRNA targets. Due to the absence of $C$. cajan target candidates in the psRNATarget server, the CDS sequences of $C$. cajan were used as target candidates. For 259 miRNAs, belonging to 180 families, 1373 target sequences were predicted. In order to characterise the targets, BLASTX was used with the predicted target sequences as query and the entire protein sequences of Viridiplantae as subject. Using $80 \%$ sequence identity cut-off, 298 targets for 122 miRNAs were characterised (Additional file 2: Table S2).

In majority of the cases, the predicted targets in this study were in accordance with the already published reports in other plant species. Wu, et al. [62] have showed that miR156 and miR172 families work in coordination to regulate the transition from the juvenile to the adult phase of plants. miR156 targets squamosa promoter binding protein-Like (SPL) transcription factor (TF) gene family to control the transition from the vegetative phase to the floral phase in Arabidopsis, rice and maize [63-68]. The cca-miR156b also targets SPL and is in agreement with the observation found in the literature. Members of the miR164 family target the NAC family of TF genes in A. thaliana, Picea abies and Vitis vinifera [69-73]. The NAC family of TFs play a major role in regulation of the boundary domain around developing primordia at the shoot apical and floral meristems [74]. ccamiR164e also targets NAC domain proteins. Scarecrow-like transcription factor is already an established target for miR171 family in Arabidopsis [75] and Oryza sativa [76]. Similar results were obtained in our study where ccamiR171b was predicted to bind Scarecrow-like (SCL) TF. SCL TFs are known to negatively regulate chlorophyll biosynthesis by suppressing the expression of the key gene PROTOCHLOROPHYLLIDE OXIDOREDUCTASE (POR). The miR172 family control plant development by regulating the trichome growth in Arabidopsis [62]. It is already established that MYB transcription factors are the negative controllers of the trichome growth [77]. The cca-miR172b family targets the MYB transcription factor mRNAs, and by cleaving these transcription factors they positively control the trichome growth. miR172 functions in regulating the transitions between developmental stages and in specifying floral organ identity. During flower development, miRNA172 represses the expression of APETALA2 (AP2) [78]. This regulation is crucial for the proper development of the reproductive organs and for the timely termination of floral stem cells [79]. The cca-miR172c targets floral homeotic protein AP2. The cca-miR397a targets laccase (LAC) enzymes, and is in agreement with established targets of miR397 family in A. thaliana, Populus trichocarpa and O. sativa. In rice, it is reported that the miR397 overexpression leads to greater 
Table 1 Distribution of miRNAs across various miRNA families.

\begin{tabular}{|c|c|c|}
\hline $\begin{array}{l}\text { Number of } \\
\text { members }\end{array}$ & miRNA families & $\begin{array}{l}\text { Number of } \\
\text { miRNA families }\end{array}$ \\
\hline 1 & $\begin{array}{l}\text { miR403, miR417, miR444, miR476, miR478, miR535, miR771, miR774, miR781, miR816, miR825, miR827, miR831, miR835, } \\
\text { miR838, miR854, miR857, miR900, miR952, miR1025, miR1039, miR1061, miR1087, miR1088, miR1097, miR1128, miR1130, } \\
\text { miR1153, miR1171, miR1217, miR1426, miR1428, miR1430, miR1439, miR1446, miR1507, miR1510, miR1518, miR1520, } \\
\text { miR1535, miR1852, miR1854, miR1916, miR1917, miR2055, miR2079, miR2086, miR2090, miR2101, miR2102, miR2105, } \\
\text { miR2108, miR2118, miR2119, miR2199, miR2275, miR2600, miR2604, miR2608, miR2611, miR2642, miR2646, miR2657, } \\
\text { miR2671, miR2866, miR2871, miR2878, miR2905, miR2912, miR2920, miR2923, miR2928, miR3433, miR3436, miR3438, } \\
\text { miR3441, miR3444, miR3447, miR3512, miR3515, miR3522, miR3626, miR3627, miR3629, miR3630, miR3631, miR3704, } \\
\text { miR3712, miR3950, miR3979, miR4223, miR4237, miR4238, miR4244, miR4249, miR4340, miR4414, miR5039, miR5055, } \\
\text { miR5075, miR5139, miR5140, miR5171, miR5174, miR5183, miR5201, miR5205, miR5219, miR5234, miR5237, miR5248, } \\
\text { miR5253, miR5261, miR5264, miR5265, miR5285, miR5288, miR5291, miR5292, miR5368, miR5372, miR5373, miR5374, } \\
\text { miR5379, miR5382, miR5521, miR5523, miR5532, miR5555, miR5558, miR5561, miR5668, miR5672, miR5716, miR5722, } \\
\text { miR5745, miR5757, miR5770, miR5773, miR5775, miR5778, miR5828, miR5837, miR6034, miR6111, miR6140, miR6148, } \\
\text { miR6173, miR6182, miR6191, miR6196, miR6230, miR6231, miR6271, miR6291, miR6443, miR6449, miR6457, miR6459, } \\
\text { miR6462, miR6466, miR6476, miR6478, miR6483, miR6485, miR7124, miR7125, miR7127, miR7484, miR7488, miR7508, } \\
\text { miR7516, miR7532, miR7534, miR7540, miR7545, miR7696, miR7728, miR7736, miR7741, miR77455, miR7753, miR7757, } \\
\text { miR7767, miR7812, miR7814, miR7816, miR7817, miR7982, miR8007, miR8014, miR8030, miR8035, miR8044, miR8047, } \\
\text { miR8049, miR8123 }\end{array}$ & 197 \\
\hline 2 & $\begin{array}{l}\text { miR158, miR160, miR161, miR162, miR164, miR168, miR394, miR397, miR398, miR408, miR414, miR419, miR530, miR837, } \\
\text { miR846, miR862, miR868, miR1023, miR1027, miR1030, miR1046, miR1051, miR1134, miR1320, miR1508, miR1511, } \\
\text { miR1512, miR1514, miR1525, miR1527, miR1533, miR1534, miR2089, miR2093, miR2595, miR2606, miR2607, miR2628, } \\
\text { miR2630, miR2641, miR2650, miR2655, miR2665, miR2673, miR2868, miR3434, miR3711, miR3951, miR4233, miR4246, } \\
\text { miR4248, miR4371, miR4376, miR4413, miR4415, miR5040, miR5041, miR5054, miR5057, miR5142, miR5240, miR5255, } \\
\text { miR5256, miR5257, miR5260, miR5281, miR5369, miR5512, miR5559, miR5565, miR5712, miR5721, miR5741, miR6135, } \\
\text { miR6169, miR6202, miR6218, miR6232, miR6281, miR6299, miR6300, miR6464, miR7535, miR7543, miR7742, miR7776, } \\
\text { miR7822, miR7823, miR7834, miR8051, miR8140 }\end{array}$ & 91 \\
\hline 3 & $\begin{array}{l}\text { miR390, miR395, miR400, miR437, miR828, miR829, miR859, miR860, miR902, miR1044, miR1438, miR1521, miR1863, } \\
\text { miR2111, miR2676, miR2873, miR2931, miR4245, miR5163, miR6025, miR6470, miR7699, miR8011, miR8041 }\end{array}$ & 24 \\
\hline 4 & miR159, miR172, miR393, miR399, miR1516, miR2592, miR3513, miR5031, miR7701, miR8005, miR8040 & 11 \\
\hline 5 & miR166, miR821, miR1078, miR1435, miR1522, miR5185, miR6288 & 7 \\
\hline 6 & miR319, miR396, miR1530, miR5568 & 4 \\
\hline 7 & miR156, miR482, miR845 & 3 \\
\hline 8 & miR167 & 1 \\
\hline 9 & miR169 & 1 \\
\hline 10 & miR477 & 1 \\
\hline 14 & miR1710 & 1 \\
\hline
\end{tabular}
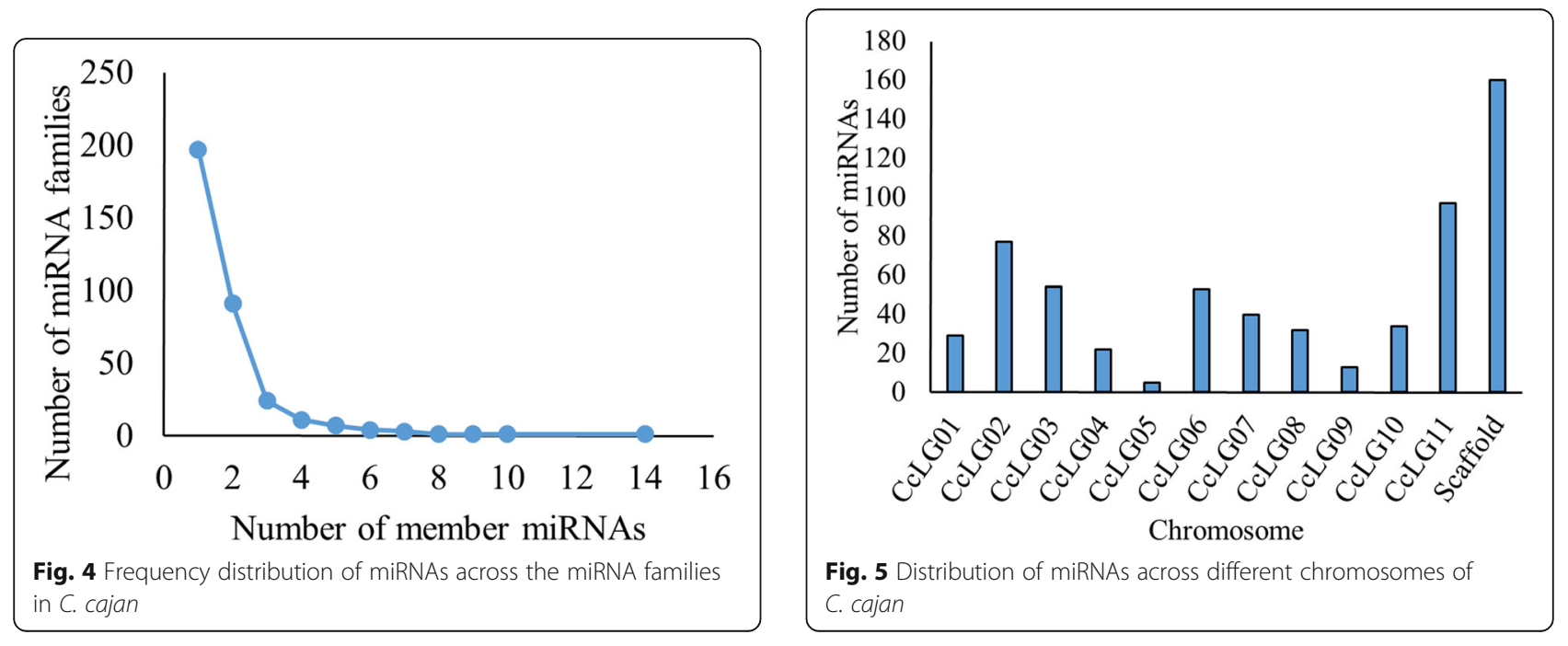
Table 2 Distribution of SSR signatures in various miRNA families of Viridiplantae, Fabaceae and C. cajan

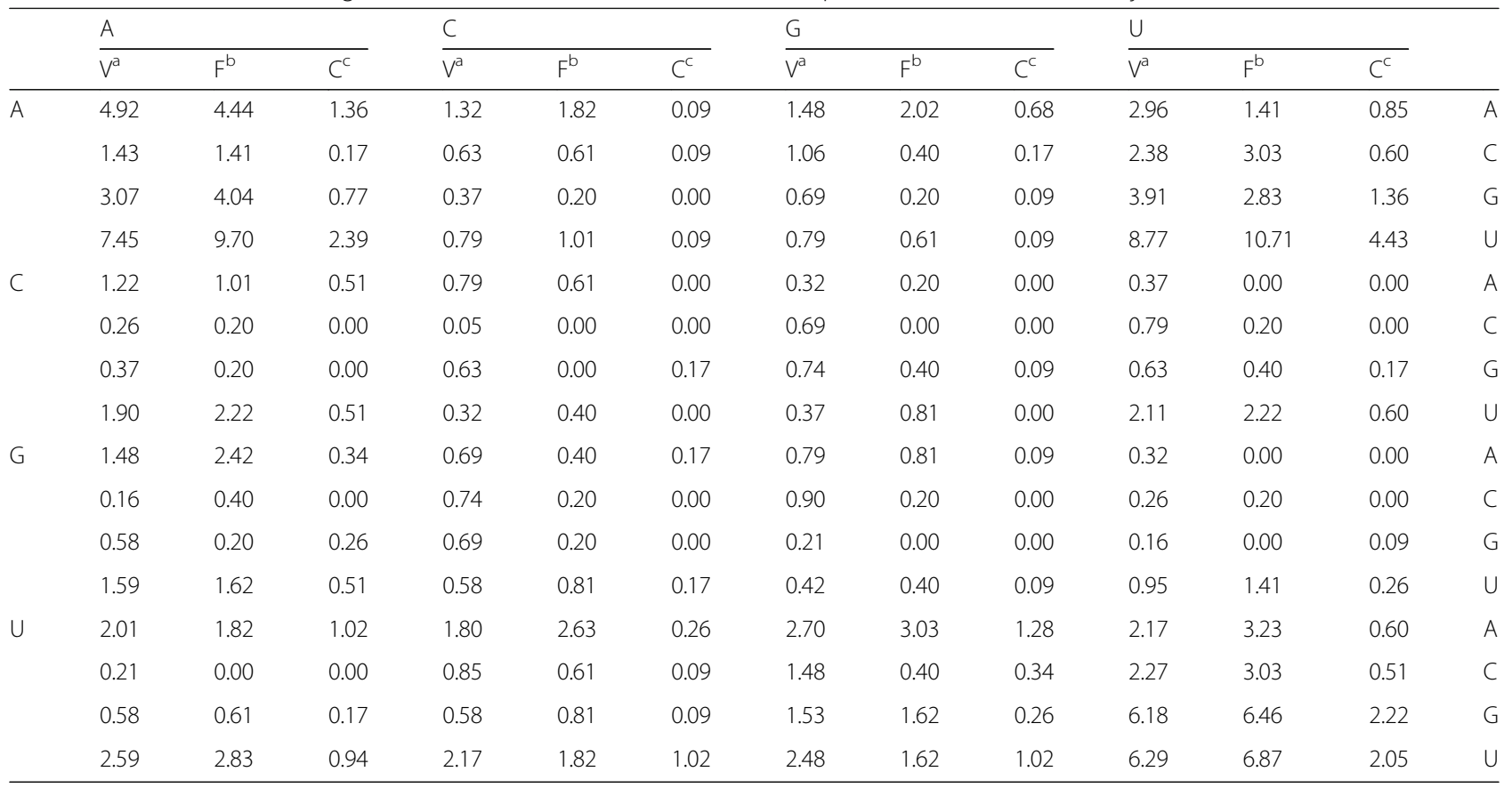

$\mathrm{V}^{\mathrm{a}}$ - The percentage of miRNA families belonging to Viridiplantae with a particular signature SSR

$\mathrm{F}^{\mathrm{b}}$ - The percentage of miRNA families belonging to Fabaceae with a particular signature SSR. The data for $\mathrm{V}^{\mathrm{a}}$ and $\mathrm{F}^{\mathrm{b}}$ are taken from our previous study [16]

$C^{C}$ - The percentage of miRNA families belonging to $C$. cajan with a particular signature SSR. There are 118 miRNA families to which $C$. cajan miRNAs belong

number of branches, increased number of grains per main panicle, increased grain size and substantially enhanced grain yield. In case of $A$. thaliana, overexpression of miR397b causes a reduction in lignification of vascular and interfascicular tissue as well as an increase in inflorescence shoots number and seed size.

The UniProt proteome, UP000075243, was used to map the target mRNAs and retrieve the corresponding UniProt protein identifiers. Of the 1373 targets, 1312 were mapped to the proteome. The visualization of these targets is provided as an interaction network between the miRNA and the corresponding UniProt entry in Fig. 7(a). The network consists of 1525 nodes. The number of targets ranges from 1 to 111 mRNAs (Fig. 7(b)). The highest number of targets is observed in cca-miR8123a. The characterized targets for cca-miR8123a includes mRNAs coding for ribosomal

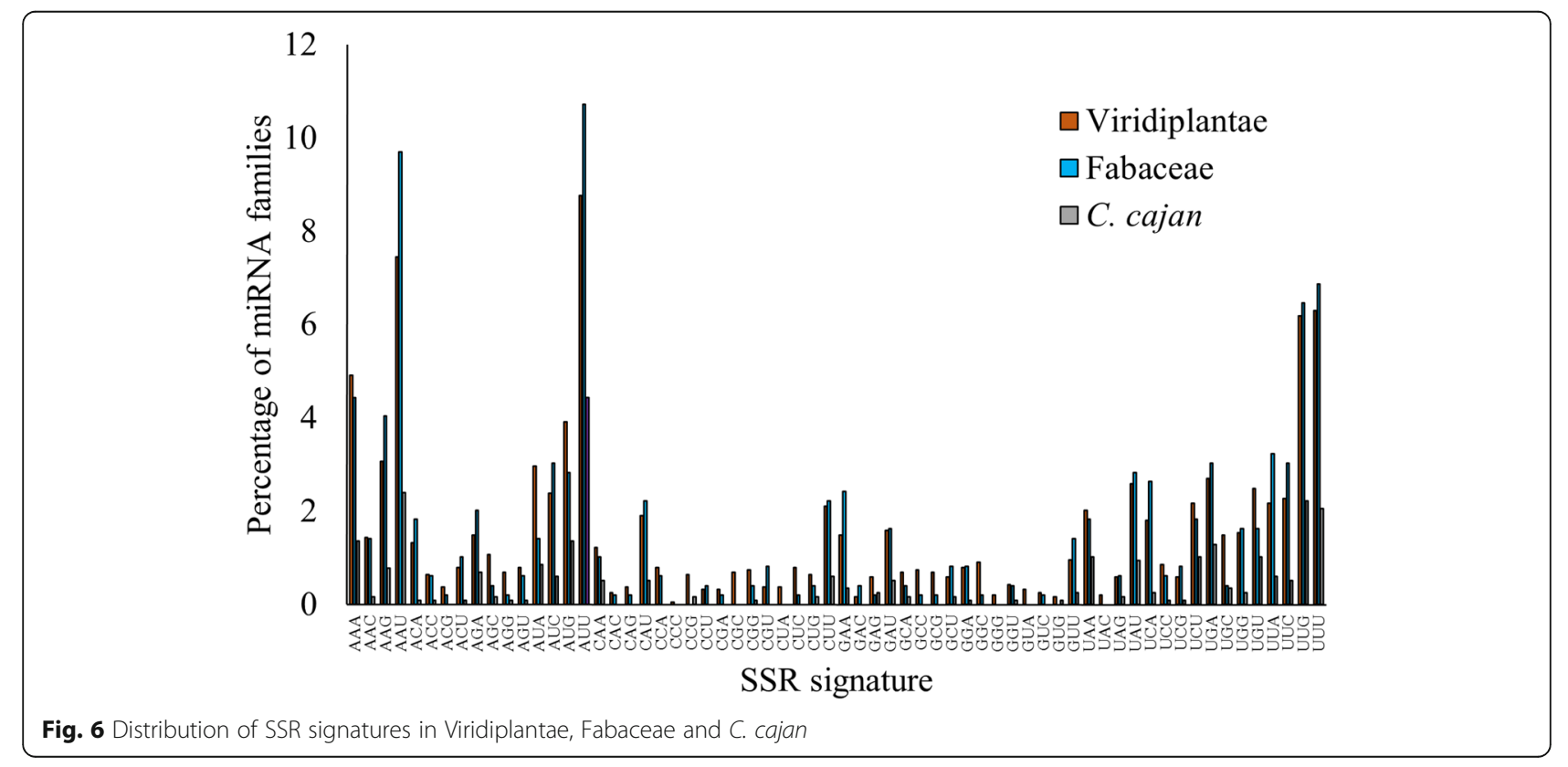




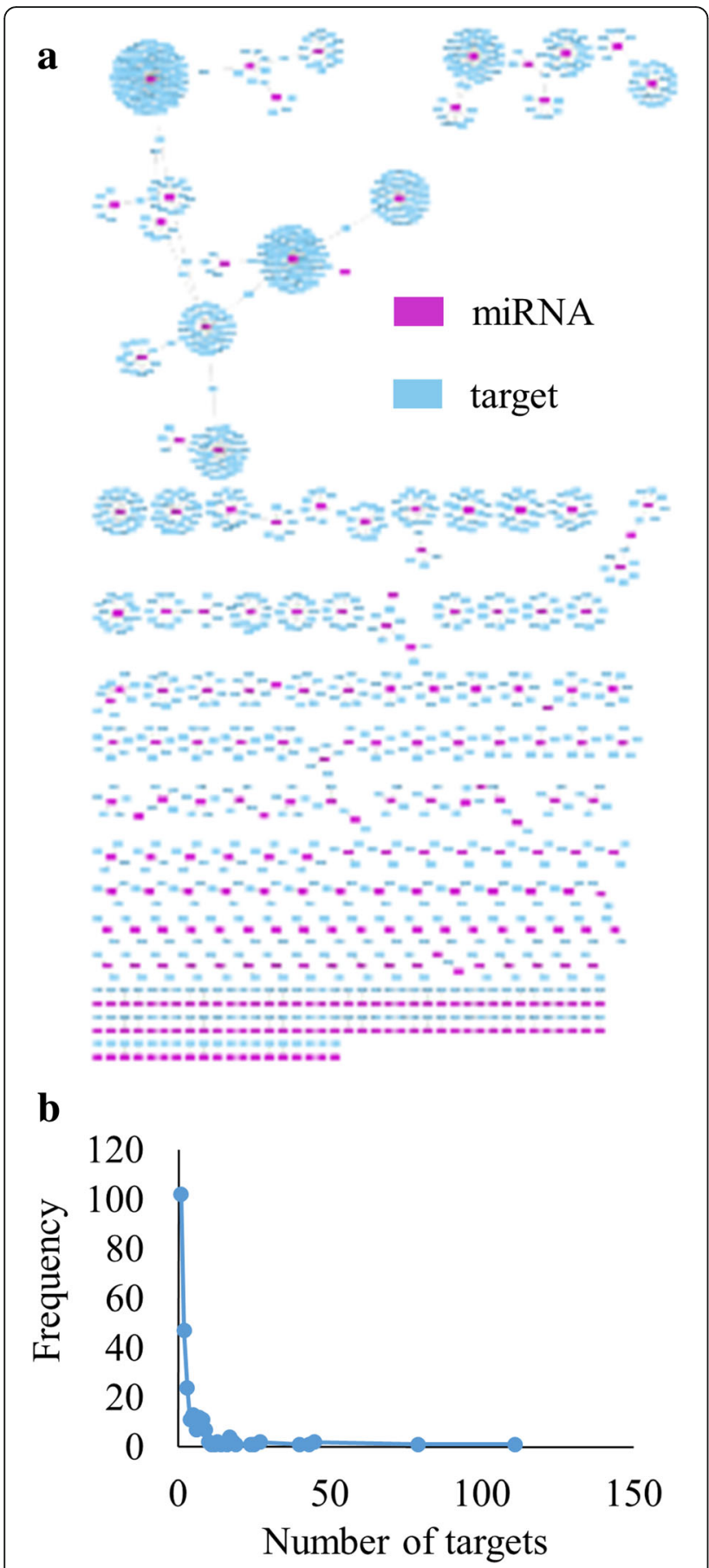

Fig. 7 miRNA targets on coding sequences. a Interaction network of miRNA and protein coding targets. $\mathbf{b}$ Frequency distribution of number of miRNA targets.

proteins, chaperones, kinases, transporters, receptors, signal transducers, ubiquitination proteins and spliceosomal RNAs (Additional file 2 Table S2). Another major node in the interaction network is cca-miR902a with 79 targets. The targets include mRNAs coding for RNA polymerases, kinases, U-box proteins, methyltransferase, retrotransposon proteins, hydrolases, kinases and CLIP-associated proteins. There are 102 miRNAs which target only one mRNA. For example, cca-miR171k targets the mRNA, which codes for F-box protein.

The GO annotations for the targets were taken from UniProt-GOA. The biological processes, molecular functions and cellular components of the targets are shown in Fig. 8. Under Biological process, majority of the targets (60\%) are involved in the metabolic and cellular process (Fig. 8(a)). Around $10 \%$ of the targets are responsible for the response to stimuli, while $8.5 \%$ are involved in the regulation of biological process. The remaining $(21.5 \%)$ are involved in a plethora of processes including reproduction, development, component organization, localization and other cellular processes. The molecular functions performed by the targets cover almost all aspects of plant metabolism (Fig. 8(b)). Majority of the targets perform functions in binding (52.5\%) and catalytic activity (37.5\%). The remaining $10 \%$ functions in nutrient reservation, transportation, signal reception and transduction, transportation and regulatory activities. The proteins coded by miRNA targets localize in different cellular components (Fig. 8(c)). A large number of proteins localize in membrane and membrane parts (43.7 \%), protoplasm (24.5\%), cell organelles (19.0\%), macromolecular complexes (6.4 \%) and extracellular region (5.3\%). The remaining (1.1 $\%)$ are localized in microtubules, virion parts and other regions in cell.

\section{Prediction of IncRNAs}

The full length cDNA sequences of $C$. cajan were used as the starting point for predicting the lncRNAs. The sequences longer than 200 nucleotides and does not have an ORF coding for more than 120 residues were only selected as the input for prediction pipeline. The coding potential of these sequences were used as a measure to remove the potential protein coding sequences and to retain the non-coding sequences. A total of 3919 lncRNAs were predicted by this pipeline.

lncRNAs have emerged as important regulators of gene expression in a variety of biological processes in multiple species. lncRNAs are increasingly recognized as functional regulatory components in eukaryotic gene regulation. In plants, they are transcribed by different RNA polymerases and show diverse structural features. Recent studies have showed that the lncRNAs play a major role in growth and cell differentiation [80], phosphate homeostasis [81], chromatin modification [82, 83] and protein re-localization $[84,85]$. Three major mechanisms of action are mainly proposed for the functioning of lncRNAs: decoys, scaffolds and guides [86]. IncRNAs act as decoys that prohibit the access of regulatory proteins to DNA. They also act as adaptors to bring two or more proteins into discrete complexes and guides in localizing specific proteins [87]. The miRNA target 


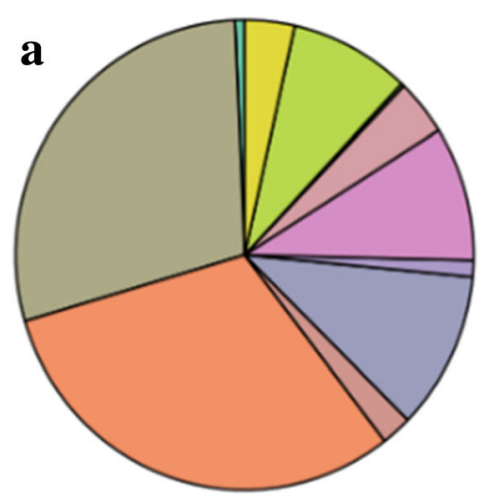

\begin{tabular}{|l|}
\hline multicellular organism development \\
metabolic process \\
cellular process \\
developmental process \\
single-organism process \\
single organism reproductive process \\
$\square$ response to stimulus \\
$\square$ localization \\
$\square$ response to other organism \\
$\square$ biological regulation \\
$\square$ cellular component organization or biogenesis
\end{tabular}

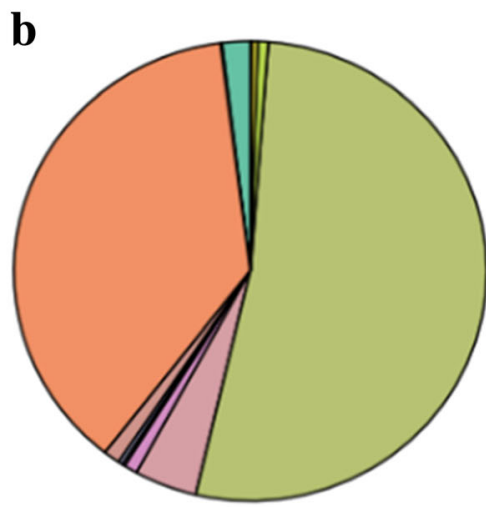

\begin{tabular}{|l|}
\hline transcription factor activity \\
transcription coactivator activity \\
catalytic activity \\
peroxidase activity \\
signal transducer activity \\
receptor activity \\
structural molecule activity \\
$\square$ transporter activity \\
$\square$ binding \\
$\square$ electron carrier activity \\
$\square$ enzyme regulator activity \\
$\square$ nutrient reservoir activity
\end{tabular}

C

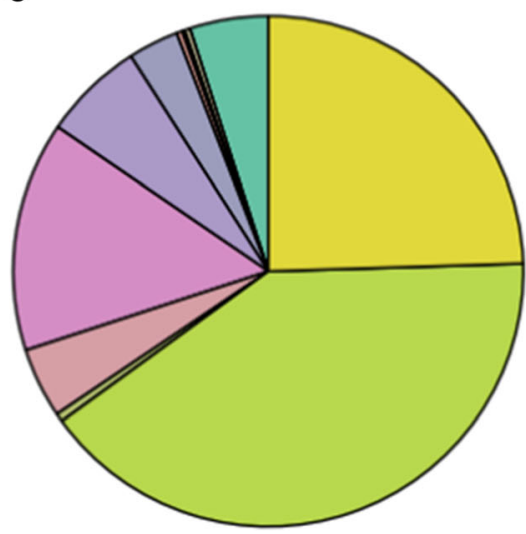

\begin{tabular}{|l|}
\hline$\square$ extracellular region \\
$\square$ extracellular space \\
$\square$ cell \\
$\square$ microtubule \\
$\square$ membrane \\
$\square$ macromolecular complex \\
$\square$ organelle \\
$\square$ organelle part \\
$\square$ virion part \\
$\square$ membrane part \\
$\square$ cell part \\
\hline$\square$
\end{tabular}

Fig. 8 Targets of miRNA distributed among three different GO terms: (a) Biological processes, (b) Molecular functions and (c) Cellular components

mimicking by lncRNA can be exemplified with Induced by Phosphate Starvation1 (IPS1) lncRNA, which has a stretch of 23 conserved nucleotides that is partially complementary to miR399. The IPS1 acts as a non-cleavable target mimic for miR399 in Medicago truncatula [88], rice [89] and Arabidopsis [90, 91]. Chromatin remodelling is demonstrated by the action of two classes of lncRNAs identified in the regulation of FLC (Flowering Locus C) expression. FLC is a floral repressor, which is repressed during the process of vernalization and it is mediated by polycomb repressive complex $P R C 2$, which is a repressive chromatin modifier. Two classes of lncRNAs - cold induced antisense intragenic RNA (COOLAIR) and cold assisted intronic non-coding RNA (COLDAIR) are involved in this process of stable silencing of FLC [82, 92-94]. The transcription of COOLAIR is repressed in warm temperatures by stabilization of a RNA-DNA hybrid structure (R-loop) in its promoter region [95]. The COLDAIR is involved in the enrichment of H3K27me3 by direct interaction with CURLY LEAF (CLF), which is a component of $P R C 2$, thereby repressing $F L C$ [82]. 


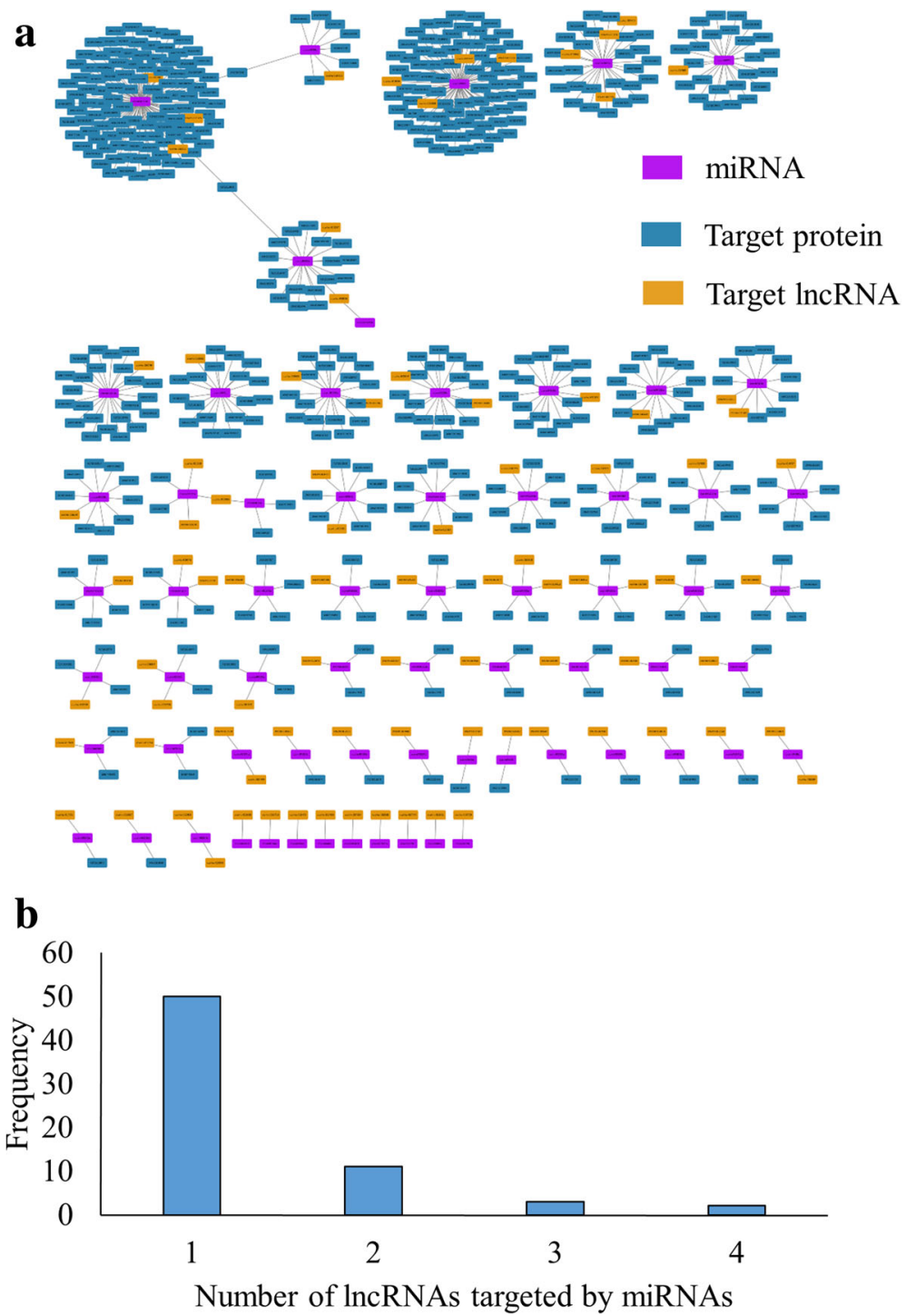

Fig. 9 miRNA targets on IncRNAs. a Interaction network of miRNA and their coding and non-coding targets. (b) Frequency distribution of number of miRNA targets on IncRNAs

\section{Prediction of miRNA targets on IncRNAs}

In this study, we have identified both the miRNAs and lncRNAs belonging to C. cajan. In order to study the direct targeting of IncRNAs by miRNAs, we have identified the targets of lncRNAs on miRNAs using psRNATarget server. A total of 66 miRNAs were identified to target 87 lncRNAs. The details of miRNAs, targeting lncRNAs, are available in the Additional file 3: Table S3. The interaction network of miRNAs that target lncRNAs is shown in Fig. 9(a). The network consists of 665 nodes. The number of lncRNAs targeted by a single miRNA varies from one to four, with a majority of them (76\%) targeting only one (Fig. 9(b)). ccamiR3979a and cca-miR902a targets four lncRNAs. These
miRNAs also have relatively higher number of protein targets, 26 and 79 respectively. cca-miR8123a, which has the highest number of proteins targets, has three lncRNAs as targets. cca-miR1527a and cca-miR403a has three target lncRNAs, however, both of them target two proteins each.

\section{Conclusion}

In the present study, we have identified the miRNAs from the genome of C. cajan and their corresponding targets. A total of 616 miRNAs belonging to 341 different families were identified. Of the identified miRNAs, 578 are novel that are not reported in the MiRBase 21. We have also identified 1379 targets for 259 miRNAs, of which 298 were 
characterized at protein level. Moreover, we have identified 3919 lncRNAs of C. cajan, 87 of which are found to be targeted by 66 miRNAs. It is well known that ncRNAs and their target mimics has the potential to be used for crop improvement programmes as proper management of them can generate crop cultivars with improved agronomic traits leading to increased yield and high nutritional value. Thorough understanding of interaction of miRNAs and their targets can provide valuable insight into molecular pathways controlling plant stress responses. Accordingly, our findings will enhance the knowledge of ncRNAs in economically important pulse crop C. cajan and their role in PTGR, will contribute in genome editing and thereby development of better crop varieties.

\section{Additional files}

Additional file 1: Table S1. Predicted miRNAs of C. cajan. (PDF $955 \mathrm{~kb}$ ) Additional file 2: Table S2. Predicted targets of $C$. cajan miRNAs. (PDF $193 \mathrm{~kb}$ )

Additional file 3: Table S3. miRNAs targeting IncRNAs in C. cajan. (PDF $46 \mathrm{~kb}$ )

\section{Abbreviations}

PTGR: post transcriptional regulation of gene expression; ncRNAs: non-coding RNAs; sncRNAs: small non-coding RNAs; IncRNAs: long non-coding RNAs; miRNAs: microRNAs; ceRNAs: competing endogenous RNAs; premiRs: precursor miRNAs; MFEl: Minimal Folding Free Energy Index; NQ: normalised Shannon entropy; Npb: normalized base-pairing propensity; ND: normalized base-pair distance; SSR: simple sequence repeat; CDS: coding DNA sequences; ORF: open reading frame

\section{Acknowledgements}

CN is thankful to the IIT Kharagpur for research fellowship. RPB and JB acknowledge DBT, India.

\section{Funding}

None.

\section{Availability of data and materials}

All data generated or analysed during this study are included in this published article and its Additional files 1, 2, 3.

\section{Authors' contributions}

RPB and JB conceived the study and participated in its design and coordination. CN and AT performed the study. CN, AT, JB and RPB wrote the manuscript.

\section{Ethics approval and consent to participate}

Not applicable.

\section{Consent for publication}

Not applicable.

\section{Competing interests}

The authors declare that they have no competing interests.

\section{Publisher's Note}

Springer Nature remains neutral with regard to jurisdictional claims in published maps and institutional affiliations.

\section{Author details}

'Computational Structural Biology Lab, Department of Biotechnology, Indian Institute of Technology Kharagpur, Kharagpur, India. ${ }^{2}$ Department of Biotechnology, Visva-Bharati, Santiniketan, India. ${ }^{3}$ Present address: Molecular and Computational Biology, Department of Biological Sciences, University of Southern California, Los Angeles, California, USA.

Received: 3 May 2017 Accepted: 23 October 2017

Published online: 15 November 2017

\section{References}

1. Singh $\mathrm{U}$, Eggum $\mathrm{BO}$. Factors affecting the protein quality of pigeonpea (Cajanus cajan L). Plant Foods for Human Nutrition. 1984;34(4):273-83.

2. Sharma S, Agarwal N, Verma P: Pigeon pea (Cajanus cajan L.): A Hidden Treasure of Regime Nutrition. Journal of Functional And Environmental Botany 2011, 1(2):91-101

3. Nene Y, Hall SD, Sheila V: The pigeonpea: CAB International; 1990

4. Flower D, Ludlow M. Variation among accessions of pigeonpea (Cajanus cajan) in osmotic adjustment and dehydration tolerance of leaves. Field Crops Res. 1987;17(3):229-43.

5. Subbarao GV, Chauhan YS, Johansen C. Patterns of osmotic adjustment in pigeonpea - its importance as a mechanism of drought resistance. Eur J Agron. 2000;12(3-4):239-49.

6. Sinha SK: Food legumes: distribution, adaptability and biology of yield: FAO; 1977

7. Saxena K, Kumar R, Rao P. Pigeonpea nutrition and its improvement. J Crop Prod. 2002;5(1-2):227-60.

8. Saxena KB, Kumar RV, Sultana R. Quality nutrition through pigeonpea-a review. Health. 2010;2(11):1335.

9. Pal D, Mishra P, Sachan N, Ghosh A: Biological activities and medicinal properties of Cajanus cajan (L) Millsp, vol. 2; 2011.

10. Kompelli SK, Kompelli VSP, Enjala C, Suravajhala P. Genome-wide identification of miRNAs in pigeonpea (Cajanus cajan L). Aust J Crop Sci. 2015;9(3):215-22.

11. Kozomara A, Griffiths-Jones S. miRBase: annotating high confidence microRNAs using deep sequencing data. Nucleic Acids Res. 2014;42(D1):D68-73.

12. Chi X, Yang Q, Chen X, Wang J, Pan L, Chen M, Yang Z, He Y, Liang X, Yu S. Identification and characterization of microRNAs from peanut (Arachis hypogaea L.) by high-throughput sequencing. PloS one. 2011;6(11):e27530.

13. Guo N, Ye W, Yan Q, Huang J, Wu Y, Shen D, Gai J, Dou D, Xing H. Computational identification of novel microRNAs and targets in Glycine max. Mol Biol Rep. 2014;41(8):4965-75.

14. Hu J, Sun L, Ding Y. Identification of conserved microRNAs and their targets in chickpea (Cicer arietinum L). Plant Signal Behav. 2013;8(4):e23604.

15. Hu J, Zhang H, Ding Y. Identification of conserved microRNAs and their targets in the model legume Lotus japonicus. J Biotechnol. 2013;164(4):520-4.

16. Nithin C, Patwa N, Thomas A, Bahadur RP, Basak J. Computational prediction of miRNAs and their targets in Phaseolus vulgaris using simple sequence repeat signatures. BMC Plant Biol. 2015;15:140.

17. Zhu J, Li W, Yang W, Qi L, Han S. Identification of microRNAs in Caragana intermedia by high-throughput sequencing and expression analysis of 12 microRNAs and their targets under salt stress. Plant Cell Rep. 2013;32(9): 1339-49.

18. Zhang BH, Pan XP, Cox SB, Cobb GP, Anderson TA. Evidence that miRNAs are different from other RNAs. Cell Mol Life Sci. 2006;63(2):246-54.

19. Ng Kwang Loong S, Mishra SK. Unique folding of precursor microRNAs: quantitative evidence and implications for de novo identification. RNA. 2007;13(2):170-87.

20. Chen M, Tan Z, Jiang J, Li M, Chen H, Shen G, Yu R. Similar distribution of simple sequence repeats in diverse completed Human Immunodeficiency Virus Type 1 genomes. FEBS Lett. 2009;583(17):2959-63.

21. Lipshitz H, Peattie D, Hogness D. Novel transcripts from the Ultrabithorax domain of the bithorax complex. Genes Dev. 1987:1(3):307-22.

22. Derrien T, Johnson R, Bussotti G, Tanzer A, Djebali S, Tilgner H, Guernec G, Martin D, Merkel A, Knowles DG, et al. The GENCODE v7 catalog of human long noncoding RNAs: Analysis of their gene structure, evolution, and expression. Genome Res. 2012;22(9):1775-89.

23. Dieci G, Fiorino G, Castelnuovo M, Teichmann M, Pagano A. The expanding RNA polymerase III transcriptome. Trends Genet. 2007;23(12):614-22.

24. The FANTOM Consortium, Carninci P, Kasukawa T, Katayama S, Gough J, Frith MC, Maeda N, Oyama R, Ravasi T, Lenhard B, et al. The Transcriptional Landscape of the Mammalian Genome. Science. 2005;309(5740):1559-63.

25. Louro R, El-Jundi T, Nakaya HI, Reis EM, Verjovski-Almeida S. Conserved tissue expression signatures of intronic noncoding RNAs transcribed from human and mouse loci. Genomics. 2008:92(1):18-25. 
26. Mercer TR, Dinger ME, Sunkin SM, Mehler MF, Mattick JS. Specific expression of long noncoding RNAs in the mouse brain. Proc Natl Acad Sci USA. 2008; 105(2):716-21.

27. Nie L, HJ W, Hsu JM, Chang SS, Labaff AM, Li CW, Wang Y, Hsu JL, Hung MC. Long non-coding RNAs: versatile master regulators of gene expression and crucial players in cancer. Am J Transl Res. 2012;4(2):127-50.

28. Mazo A, Hodgson JW, Petruk S, Sedkov Y, Brock HW. Transcriptional interference: an unexpected layer of complexity in gene regulation. J Cell Sci. 2007;120(16):2755-61.

29. Hirota K, Miyoshi T, Kugou K, Hoffman CS, Shibata T, Ohta K. Stepwise chromatin remodelling by a cascade of transcription initiation of noncoding RNAs. Nature. 2008;456(7218):130-4.

30. Martianov I, Ramadass A, Serra Barros A, Chow N, Akoulitchev A. Repression of the human dihydrofolate reductase gene by a non-coding interfering transcript. Nature. 2007;445(7128):666-70.

31. Mariner PD, Walters RD, Espinoza CA, Drullinger LF, Wagner SD, Kugel JF, Goodrich JA. Human Alu RNA Is a Modular Transacting Repressor of mRNA Transcription during Heat Shock. Mol Cell. 2008;29(4):499-509.

32. Nguyen VT, Kiss T, Michels AA, Bensaude O. 7SK small nuclear RNA binds to and inhibits the activity of CDK9/cyclin T complexes. Nature. 2001;414(6861): 322-5.

33. Willingham AT, Orth AP, Batalov S, Peters EC, Wen BG, Aza-Blanc P, Hogenesch JB, Schultz PG. A Strategy for Probing the Function of Noncoding RNAs Finds a Repressor of NFAT. Science. 2005;309(5740):1570-3.

34. Beltran M, Puig I, Peña C, García JM, Álvarez AB, Peña R, Bonilla F, de Herreros AG. A natural antisense transcript regulates Zeb2/Sip1 gene expression during Snail1-induced epithelial-mesenchymal transition. Genes Dev. 2008;22(6):756-69.

35. Golden DE, Gerbasi VR, Sontheimer EJ. An Inside Job for siRNAs. Mol Cell. 2008;31(3):309-12

36. Kozomara A. Griffiths-Jones S: miRBase: annotating high confidence microRNAs using deep sequencing data. Nucleic Acids Res. 2014; 42(Database issue):D68-73.

37. Varshney RK, Chen WB, Li YP, Bharti AK, Saxena RK, Schlueter JA, Donoghue MTA, Azam S, Fan GY, Whaley AM, et al. Draft genome sequence of pigeonpea (Cajanus cajan), an orphan legume crop of resource-poor farmers. Nat Biotechnol. 2012;30(1):83-U128.

38. Schmutz J, McClean PE, Mamidi S, GA W, Cannon SB, Grimwood J, Jenkins J, Shu S, Song Q, Chavarro C, et al. A reference genome for common bean and genome-wide analysis of dual domestications. Nat Genet. 2014;46(7):707-13.

39. NCBI. Resource Coordinators: Database resources of the National Center for Biotechnology Information. Nucleic Acids Res. 2016;44(D1):D7-D19.

40. The UniProt Consortium. UniProt: the universal protein knowledgebase. Nucleic Acids Res. 2017:45(D1):D158-69.

41. Huntley RP, Sawford T, Mutowo-Meullenet P, Shypitsyna A, Bonilla C, Martin MJ, O'Donovan C. The GOA database: Gene Ontology annotation updates for 2015. Nucleic Acids Res. 2015:43(D1):D1057-63.

42. O'Donovan C, Martin MJ, Gattiker A, Gasteiger E, Bairoch A, Apweiler R. High-quality protein knowledge resource: SWISS-PROT and TrEMBL. Briefings Bioinf. 2002;3(3):275-84.

43. Camacho C, Coulouris G, Avagyan V, Ma N, Papadopoulos J, Bealer K, Madden TL. BLAST+: architecture and applications. BMC Bioinformatics. 2009;10(1):421.

44. Schultes EA, Hraber PT, LaBean TH. Estimating the contributions of selection and self-organization in RNA secondary structure. J Mol Evol. 1999;49(1):76-83.

45. Huynen M, Gutell R, Konings D. Assessing the reliability of RNA folding using statistical mechanics. J Mol Biol. 1997;267(5):1104-12.

46. Moulton V, Zuker M, Steel M, Pointon R, Penny D. Metrics on RNA secondary structures. J Comput Biol. 2000;7(1-2):277-92.

47. Boerner S, McGinnis KM. Computational Identification and Functional Predictions of Long Noncoding RNA in Zea mays. PloS one. 2012;7(8):e43047.

48. Rice P, Longden I, Bleasby A. EMBOSS: The European Molecular Biology Open Software Suite. Trends Genet. 2000;16(6):276-7.

49. Kong L, Zhang Y, Ye Z-Q, Liu X-Q, Zhao S-Q, Wei L, Gao G. CPC: assess the protein-coding potential of transcripts using sequence features and support vector machine. Nucleic Acids Res. 2007;35(suppl 2):W345-9.

50. Wang L, Park HJ, Dasari S, Wang S, Kocher J-P, Li W. CPAT: Coding-Potential Assessment Tool using an alignment-free logistic regression model. Nucleic Acids Res. 2013:41(6):e74.

51. Weikard R, Hadlich F, Kuehn C. Identification of novel transcripts and noncoding RNAs in bovine skin by deep next generation sequencing. BMC Genomics. 2013;14(1):789.
52. Altschul SF, Gish W, Miller W, Myers EW, Lipman DJ. Basic local alignment search tool. J Mol Biol. 1990;215(3):403-10.

53. Dai $X$, Zhao PX. psRNATarget: a plant small RNA target analysis server. Nucleic Acids Res. 2011;39(Web Server issue):W155-9.

54. Zhang Y: miRU: an automated plant miRNA target prediction server. Nucleic Acids Res 2005, 33(Web Server issue):W701-704.

55. Kertesz M, lovino N, Unnerstall U, Gaul U, Segal E. The role of site accessibility in microRNA target recognition. Nat Genet. 2007;39(10):1278-84.

56. Shannon P, Markiel A, Ozier O, Baliga NS, Wang JT, Ramage D, Amin N, Schwikowski B, Ideker T. Cytoscape: a software environment for integrated models of biomolecular interaction networks. Genome Res. 2003;13(11):2498-504

57. Zhang B, Pan X, Cannon CH, Cobb GP, Anderson TA. Conservation and divergence of plant microRNA genes. Plant J. 2006;46(2):243-59.

58. Carrington JC, Ambros $\mathrm{V}$. Role of microRNAs in plant and animal development. Science. 2003;301(5631):336-8.

59. Djuranovic S, Nahvi A, Green R. A Parsimonious Model for Gene Regulation by miRNAs. Science. 2011;331(6017):550-3.

60. Brennecke J, Stark A, Russell RB, Cohen SM. Principles of MicroRNA-Target Recognition. PLoS Biol. 2005;3(3):e85.

61. Kidner CA, Martienssen RA. The developmental role of microRNA in plants. Curr Opin Plant Biol. 2005;8(1):38-44.

62. Wu G, Park MY, Conway SR, Wang JW, Weigel D, Poethig RS. The sequential action of miR156 and miR172 regulates developmental timing in Arabidopsis. Cell. 2009;138(4):750-9.

63. Chuck G, Cigan AM, Saeteurn K, Hake S. The heterochronic maize mutant Corngrass 1 results from overexpression of a tandem microRNA. Nat Genet. 2007;39(4):544-9.

64. Gandikota M, Birkenbihl RP, Höhmann S, Cardon GH, Saedler H, Huijser P. The miRNA156/157 recognition element in the 3' UTR of the Arabidopsis SBP box gene SPL3 prevents early flowering by translational inhibition in seedlings. Plant J. 2007;49(4):683-93.

65. Jiao Y, Wang Y, Xue D, Wang J, Yan M, Liu G, Dong G, Zeng D, Lu Z, Zhu X, et al. Regulation of OsSPL14 by OsmiR156 defines ideal plant architecture in rice. Nat Genet. 2010;42(6):541-4.

66. Miura K, Ikeda M, Matsubara A, Song X-J, Ito M, Asano K, Matsuoka M, Kitano $\mathrm{H}$, Ashikari M. OsSPL14 promotes panicle branching and higher grain productivity in rice. Nat Genet. 2010;42(6):545-9.

67. Yang L, Conway SR, Poethig RS. Vegetative phase change is mediated by a leaf-derived signal that represses the transcription of miR156. Development. 2011;138(2):245-9.

68. Yamaguchi A, M-F W, Yang L, Wu G, Poethig RS, Wagner D. The MicroRNA-Regulated SBP-Box Transcription Factor SPL3 Is a Direct Upstream Activator of LEAFY, FRUITFULL, and APETALA1. Dev Cell. 2009;17(2):268-78.

69. Larsson E, Sundström JF, Sitbon F, von Arnold S. Expression of PaNAC01, a Picea abies CUP-SHAPED COTYLEDON orthologue, is regulated by polar auxin transport and associated with differentiation of the shoot apical meristem and formation of separated cotyledons. Ann Bot. 2012;110(4):923-34.

70. Raman S, Greb T, Peaucelle A, Blein T, Laufs P, Theres K. Interplay of miR164, CUP-SHAPED COTYLEDON genes and LATERAL SUPPRESSOR controls axillary meristem formation in Arabidopsis thaliana. Plant J. 2008;55(1):65-76.

71. Kim JH, Woo HR, Kim J, Lim PO, Lee IC, Choi SH, Hwang D, Nam HG. Trifurcate Feed-Forward Regulation of Age-Dependent Cell Death Involving miR164 in Arabidopsis. Science. 2009;323(5917):1053-7.

72. Laufs $P$, Peaucelle A, Morin H, Traas J. MicroRNA regulation of the CUC genes is required for boundary size control in Arabidopsis meristems. Development. 2004;131(17):4311-22.

73. Sun G. MicroRNAs and their diverse functions in plants. Plant Mol Biol. 2011; 80(1):17-36.

74. Aida M, Ishida T, Tasaka M. Shoot apical meristem and cotyledon formation during Arabidopsis embryogenesis: interaction among the CUP-SHAPED COTYLEDON and SHOOT MERISTEMLESS genes. Development. 1999;126(8):1563-70.

75. Sunkar R, Zhu JK. Novel and stress-regulated microRNAs and other small RNAs from Arabidopsis. Plant Cell. 2004;16(8):2001-19.

76. Zhou L, Liu Y, Liu Z, Kong D, Duan M, Luo L. Genome-wide identification and analysis of drought-responsive microRNAs in Oryza sativa. J Exp Bot. 2010;61(15): 4157-68.

77. Dubos C, Stracke R, Grotewold E, Weisshaar B, Martin C, Lepiniec L. MYB transcription factors in Arabidopsis. Trends Plant Sci. 2010;15(10):573-81.

78. Chen X. A microRNA as a translational repressor of APETALA2 in Arabidopsis flower development. Science. 2004;303(5666):2022-5. 
79. Zhu QH, Helliwell CA. Regulation of flowering time and floral patterning by miR172. J Exp Bot. 2011;62(2):487-95.

80. Ben Amor B, Wirth S, Merchan F, Laporte P, d'Aubenton-Carafa Y, Hirsch J, Maizel A, Mallory A, Lucas A, Deragon JM, et al. Novel long non-protein coding RNAs involved in Arabidopsis differentiation and stress responses. Genome Res. 2009;19(1):57-69.

81. Franco-Zorrilla JM, Valli A, Todesco M, Mateos I, Puga MI, Rubio-Somoza I, Leyva A, Weigel D, Garcia JA, Paz-Ares J. Target mimicry provides a new mechanism for regulation of microRNA activity. Nat Genet. 2007;39(8):1033-7.

82. Heo JB, Sung S. Vernalization-Mediated Epigenetic Silencing by a Long Intronic Noncoding RNA. Science. 2011;331(6013):76-9.

83. He Y. Noncoding RNA-Mediated Chromatin Silencing (RmCS) in Plants. Mol Biol. 2013;2:e106.

84. Zhu Q-H, Wang M-B. Molecular Functions of Long Non-Coding RNAs in Plants. Genes. 2012;3(1):176.

85. Campalans A, Kondorosi A, Crespi M. Enod40, a short open reading framecontaining mRNA, induces cytoplasmic localization of a nuclear RNA binding protein in Medicago truncatula. Plant Cell. 2004;16(4):1047-59.

86. Wang Kevin C, Chang Howard Y. Molecular Mechanisms of Long Noncoding RNAs. Mol Cell. 2011;43(6):904-14.

87. Rinn JL, Chang HY. Genome regulation by long noncoding RNAs. Annu Rev Biochem. 2012;81:145-66.

88. Burleigh $\mathrm{SH}$, Harrison MJ. A novel gene whose expression in Medicago truncatula roots is suppressed in response to colonization by vesiculararbuscular mycorrhizal (VAM) fungi and to phosphate nutrition. Plant Mol Biol. 1997;34(2):199-208.

89. Wasaki J, Yonetani R, Shinano T, Kai M, Osaki M. Expression of the OsPI1 gene, cloned from rice roots using cDNA microarray, rapidly responds to phosphorus status. New Phytol. 2003;158(2):239-48.

90. Burleigh SH, Harrison MJ. The Down-Regulation of Mt4-Like Genes by Phosphate Fertilization Occurs Systemically and Involves Phosphate Translocation to the Shoots. Plant Physiol. 1999;119(1):241-8.

91. Martin AC, del Pozo JC, Iglesias J, Rubio V, Solano R, de La Pena A, Leyva A, Paz-Ares J. Influence of cytokinins on the expression of phosphate starvation responsive genes in Arabidopsis. Plant J. 2000;24(5):559-67.

92. Swiezewski S, Liu F, Magusin A, Dean C. Cold-induced silencing by long antisense transcripts of an Arabidopsis Polycomb target. Nature. 2009; 462(7274):799-802.

93. Helliwell CA, Robertson M, Finnegan EJ, Buzas DM, Dennis ES. VernalizationRepression of Arabidopsis FLC Requires Promoter Sequences but Not Antisense Transcripts. PloS one. 2011;6(6):e21513.

94. Heo JB, Sung S. Encoding memory of winter by noncoding RNAs. Epigenetics. 2011;6(5):544-7.

95. Sun Q, Csorba T, Skourti-Stathaki K, Proudfoot NJ, Dean C. R-Loop Stabilization Represses Antisense Transcription at the Arabidopsis FLC Locus. Science. 2013;340(6132):619-21.

\section{Submit your next manuscript to BioMed Central and we will help you at every step:}

- We accept pre-submission inquiries

- Our selector tool helps you to find the most relevant journal

- We provide round the clock customer support

- Convenient online submission

- Thorough peer review

- Inclusion in PubMed and all major indexing services

- Maximum visibility for your research

Submit your manuscript at www.biomedcentral.com/submit 